\title{
A comunicação do conhecimento científico: dados sobre a ce- leridade do processo de avaliação e de publicação de artigos científicos em periódicos da área de contabilidade
}

The communication of scientific knowledge: data on the speed of the process of evaluation and publication of scientific articles in journals in the field of accounting

Warley de Oliveira Dias

Mestre em Ciências Contábeis na Universidade Federal de Minas Gerais

Professor Substituto do Departamento de Ciências Contábeis da Universidade Federal de Minas Gerais

Endereço: Avenida Antônio Carlos, n॰ 6627, Bairro Pampulha

CEP: 31270-901 - Belo Horizonte/MG - Brasil

E-mail: warley.o.dias@bol.com.br

Telefone: (31) 3409-7061

\section{João Estevão Barbosa Neto}

Mestre em Ciências Contábeis na Universidade Federal de Minas Gerais

Professor da Faculdade Milton Campos

Endereço: Alameda da Serra, 61 - Vila da Serra - Nova Lima

CEP: 34000-000 - Belo Horizonte/MG - Brasil

E-mail: joaoestevaobarbosaneto@gmail.com

Teleone: (31) 3289-1900

\section{Jacqueline Veneroso Alves da Cunha}

Doutora em Ciências Contábeis na Universidade de São Paulo

Professora Adjunta do Departamento de Ciências Contábeis da Universidade Federal de Minas Gerais

Endereço: Avenida Antônio Carlos, n॰ 6627, Bairro Pampulha

CEP: 31270-901 - Belo Horizonte/MG - Brasil

E-mail: jvac@face.ufmg.br

Telefone: (31) 3409-7275 


\title{
Resumo
}

O objetivo do estudo é verificar as evidências de isomorfismo nas funções da controladoria das empresas faEste estudo teve como objetivo buscar evidências que permitissem identificar e analisar o período de avaliação e publicação de artigos em periódicos científicos da área de Contabilidade. Para atingir os objetivos propostos, realizou-se um estudo descritivo com utilização da estratégia de pesquisa documental em 660 artigos de oito periódicos vinculados aos cursos de pós-graduação stricto sensu em Ciências Contábeis, no período de 2004 a 2009. Os resultados demonstraram que o tempo para a avaliação e a publicação de um trabalho científico aumentou no decorrer do período analisado. Pode-se inferir que a classificação do periódico no sistema Qualis/CAPES, o tempo de existência do periódico, o reduzido número de avaliadores, o aumento da produção científica na área de Contabilidade e a nova política de avaliação da Qualis/CAPES podem ser considerados fatores que interferem no tempo de avaliação dos artigos submetidos nos periódicos da área de Contabilidade.

Palavras-chave: Produção científica em contabilidade. Periódicos. Avaliação. Periodicidade.

\begin{abstract}
In this sense, this study aimed to find evidence that would allow identification and analysis of the evaluation period and publication of articles in scientific journals in the field of accounting. To achieve the proposed objectives, we performed a descriptive study using the research strategy document of eight articles in 660 journals linked to post-graduate studies in Accounting, from 2004 to 2009. The results demonstrated that the time for evaluation and publication of scientific work has increased over the period analyzed. It can be inferred that the classification of the periodic system Qualis / CAPES, the lifetime of the journal, the small number of assessors, the increase of scientific production in the area of accounting and the new evaluation policy of Qualis / CAPES as factors that affect time evaluation of the submitted articles in accounting journals.
\end{abstract}

Keywords: Scientific production in accounting. Periodical evaluation. Periodicity.

\section{Introdução}

Atualmente, é reconhecido o papel da ciência, tecnologia e inovação como fatores diferenciadores do desenvolvimento social e econômico de países e regiões (ROCHA; FERREIRA, 2004). Nesse sentido, observa-se que o principal objetivo da ciência é a geração de conhecimento e de tecnologia, sendo a produção e a divulgação dos resultados das pesquisas um relevante impulsionador da expansão do saber.

Tahai e Rigsby (1998) inferem que a publicação dos resultados das pesquisas desempenha um importante papel no crescimento e disseminação do conhecimento científico. Diante desse contexto, observa-se a importante função dos pesquisadores de divulgar os resultados de seus estudos, disponibilizando-os à comunidade e, assim, contribuindo para a promoção do processo de comunicação científica. As pesquisas não divulgadas são consideradas inúteis, pois não chegarão elas as implicações e críticas e não serão consideradas as descobertas nem a teoria poderá ser aceita ou refutada (ANGERAMI; ALMEIDA, 1982).

Nesse sentido, para realizar a exposição de suas investigações, os pesquisadores fazem uso dos instrumentos de difusão do conhecimento para a publicação 
da produção científica gerada por eles, entre os quais pode-se citar a comunicação escrita, com destaque para livros, periódicos, relatórios técnicos, revisões de literatura e bibliografias. Assim, os periódicos, em sua perspectiva de divulgação da informação científica para a sociedade em geral, possuem relevância crescente. De acordo com Mueller (2000) os artigos científicos, publicados nos periódicos, além de oferecerem uma forma para a preservação do conhecimento neles registrado, ainda são úteis para a ampliação da comunicação entre cientistas e a divulgação de resultados de pesquisa e dos estudos acadêmicos.

A Contabilidade, como campo do conhecimento científico, também se alicerça na divulgação dos estudos de seus pesquisadores. Desse modo, os pesquisadores contábeis se interagem e divulgam suas pesquisas por meio de periódicos, teses, dissertações, relatórios, anais e atas de congressos. Oliveira (2002) argumenta que o papel fundamental da produção do conhecimento na área de Contabilidade, assim como em qualquer área do conhecimento, é o de servir de referência para praticantes e estudiosos.

Contudo, ressalta-se que alguns aspectos podem interferir na divulgação dos resultados dos trabalhos científicos. No caso da Contabilidade, observa-se um insipiente arcabouço científico quando comparada com outras áreas do conhecimento, como Administração e Economia. Outro fator é que a criação de veículos de comunicação cientifica não acompanhou o crescimento do número de pesquisadores, uma vez que em 1997 eram 250 mestres e em 2008 esse número passou para 2.187. Já o número de doutores aumentou de 55 em 1997 para 173 em 2008 (ANPCONT, 2009). Enquanto isso, até o ano de 2008 havia pouco mais de 40 revistas para publicação da pesquisa contábil (MARTINS, 2008).

Atrelado a esses fatores, que prejudicam a difusão dos artigos científicos nos periódicos especializados, encontra-se o aumento do período de avaliação dos artigos, ou seja, o tempo decorrente entre o trabalho científico ser submetido, revisado, as contribuições advindas das críticas aceitas e ajustadas e, por fim, publicado. Assim, em uma área onde a pesquisa se apresenta emergente, o escasso número de periódicos, a existência de um percentual restrito de pesquisadores que possam ser avaliadores, visto o baixo número de doutores, podem fazer com que o período de avaliação dos artigos submetidos seja afetado de forma relevante.

Mueller, Campelo e Dias (1996) ressaltam que a questão da periodicidade de publicação merece considerações especiais, já que a não tempestividade provoca a perda de confiança no trabalho. Dadas as características da disseminação científica, a questão tempo ou rapidez na publicação assume importância muito grande para o autor e para o público leitor. Pouco adianta a existência de artigos e periódicos, se não há regularidade na sua produção.

De acordo com Oliveira (2002) a periodicidade é uma informação relevante para os pesquisadores que pretendem mandar artigos para publicação, uma vez 
que a maior frequência significa que a informação circula com maior agilidade. Outro aspecto refere-se à regularidade da revista, sendo este um fator essencial para quem pretende publicar artigos, pois atesta sobre a confiabilidade do periódico no tocante à circulação das informações.

Diante desse contexto, apresenta a seguinte questão a ser investigada: Qual é a celeridade do processo de avaliação e de publicação de artigos científicos em 08 dos principais periódicos da área de Ciências Contábeis?

Assim, o presente estudo tem por objetivo geral investigar a celeridade do processo de avaliação e de publicação de artigos científicos em 08 dos principais periódicos da área de Ciências Contábeis. Outras metas são: identificar e analisar as datas de recebimento, de aceitação e de revisão dos artigos, bem como a data da publicação do estudo científico.

A pesquisa se justifica por contribuir para que o meio científico contábil tenha conhecimento do tempo em que seus estudos levam para serem divulgados, bem como o conhecimento sobre o período de avaliação e publicação de cada periódico. Dessa forma, os pares científicos poderão discutir sobre as melhores formas de tornar mais eficiente esse período e propor novas formas para a melhoria do tempo de avaliação, buscando aumentar a divulgação científica e, consequentemente, contribuir para o progresso da ciência contábil.

\section{Referencial Teórico}

\subsection{Instrumentos de Divulgação Cientifica}

A expressão "comunicação científica" foi criada na década de 1940 por John Bernal a fim de representar o processo de geração e transferência de informação científica entre pesquisadores (CHRISTOVÃO; BRAGA, 1997, p. 40). A comunicação científica compreendida como os aspectos associados à disseminação e ao uso da informação é importante para a aceitação do que é produzido cientificamente como constituinte do conhecimento científico (OLIVEIRA, 2002).

Desse modo, todo trabalho intelectual de estudiosos e pesquisadores depende de um emaranhado sistema de comunicação, que compreende canais formais e informais, os quais os cientistas utilizam tanto para comunicar os resultados que obtêm em suas pesquisas quanto para se informarem dos resultados alcançados por outros pesquisadores. O processo comunicacional ocorre por meio de canais heterogêneos e tem como emissor o próprio gerador do conhecimento científico - pesquisador ou cientista. (GARVEY, 1979).

Targino $(1999,2000)$ classifica os meios de propagação do conhecimento em canais formais, semiformais e informais de comunicação. A autora observa que o canal formal se dá por meio de diversos meios de comunicação escrita, com 
destaque para livros, periódicos, relatórios técnicos, revisões de literatura, bibliografias, entre outras. Já a comunicação científica semiformal relaciona-se com a difusão de resultados parciais de pesquisas e enquadrando-se aí as comunicações em congressos ou outros encontros científicos, publicadas ou não, confirmando a impossibilidade de posturas rígidas e definitivas (CARVALHO, 2006). Por fim, um canal informal é representado por recursos orais, como conversas e telefonemas; e por recursos escritos como cartas, fax e mensagens eletrônicas.

Entre os importantes meios de divulgação científica está o conhecimento produzido em dissertações e teses, dentro dos cursos de pós-graduação. As dissertações de mestrado e as teses de doutorado são consideradas fontes de pesquisa para se compreender o estado da arte de determinada área científica (ANTUNES et al., 2004). Uma parte relevante dos artigos e papers científicos veiculados nos canais especializados seria originada de tais documentos. Os autores retrocitados observam que as dissertações e teses preditam as linhas de pesquisa em uso e motivam os conteúdos trabalhados em situações de ensino-aprendizagem.

Outro meio de comunicação científica importante são os eventos ou os congressos científicos, os quais reúnem, pesquisadores, estudantes, profissionais e outros grupos interessados em compartilhar e obter conhecimentos sobre uma determinada área. Marchiori, Adami e Ferreira (2006) citam como principais funções dos eventos científicos proporcionar a troca de experiências entre os pesquisadores, a atualização sobre os progressos recentes de uma área e a sistematização desses avanços, a divulgação de novos conhecimentos e o delineamento de diretrizes e metas para os futuros empreendimentos numa determinada área do saber.

Ainda, como instrumento de divulgação científica, está o periódico. Segundo Sabadini, Sampaio e Koller (2009) o periódico científico ou revista científica constitui uma espécie de publicação seriada editada em fascículos. No mesmo sentido, Meadows (1999) elucida que o termo revista (journal) é uma maneira abreviada de se referir a uma coletânea de artigos científicos escritos por diferentes autores, sendo tais artigos reunidos em intervalos de tempo e distribuídos sob um título único.

Oliveira (2002) infere que os periódicos possuem uma importante função na promoção da qualidade da pesquisa e para o avanço do conhecimento, por meio da seleção e divulgação dos trabalhos. Os artigos publicados em periódicos são parte fundamental do fluxo de informação originado com a atividade científica de pesquisa. De acordo Valério (2005, p. 95), os periódicos científicos ou revistas científicas apresentam características extrínsecas e intrínsecas. Para a autora:

As características extrínsecas são: as práticas editoriais explicitadas, critérios e procedimentos para seleção e avaliação de artigos, política editorial explícita, instruções aos autores, normalização, duração do periódico (tradição, continuidade), regularidade de publicação, indexação em bases de dados nacional 
e internacional, tiragem e apresentação gráfica. As características intrínsecas são corpo editorial, sistema de avaliação por pares e integração do autor com o leitor (VALÉRIO, 2005).

Diversos estudos sobre periódicos são encontrados na literatura. Como exemplo está o estudo de Zeff (1996) que identificou 77 periódicos científicos de Contabilidade editados em inglês. $\mathrm{O}$ autor também analisou os motivos para o aparecimento de novos periódicos e verificou a condição referente à distribuição dos periódicos pelas livrarias e sua inclusão em catálogos impressos e em bancos de dados eletrônicos.

Prather e Rueschhoff (1996) analisaram os periódicos acadêmicos de Contabilidade dos Estados Unidos sob a ótica dos estudos em Contabilidade internacional, analisando o número e a qualidade dos artigos e demonstrando a metodologia utilizada nos trabalhos sobre esse tema. Tahai e Rigbsy (1998) analisaram a duração da pesquisa contábil por meio de citações em 48 periódicos acadêmicos.

Frezatti (2000), por meio de um estudo exploratório, identificou as características de algumas das principais tendências observadas por 118 revistas científicas que veiculam temas de interesse da classe contábil em língua inglesa. Para tanto, o autor observou a área da revista, a frequência de publicação, a dimensão de métodos quantitativos aplicados.

Oliveira (2002) pesquisou as características dos periódicos brasileiros de Contabilidade por meio de critérios como corpo editorial, forma de acesso e distribuição, periodicidade, normalização, autoria e temas. Mendonça Neto et al. (2004) analisaram a distribuição, as características metodológicas, a evolução, a temática e a produtividade dos autores das publicações cientificas em Contabilidade no período de 1990 a 2003, nas revistas nacionais classificadas como conceito A pela Capes. Já Lowe e Locke (2005) classificaram os periódicos científicos de Contabilidade pela percepção da comunidade acadêmica do Reino Unido.

Portanto, comunicar a informação científica constitui-se uma regra essencial, conforme denota Meadows (1999) ao afirmar que o aumento do conhecimento depende de sua comunicação. Frezatti (2000) infere que a publicação em periódicos especializados representa um importante trabalho dos pesquisadores, uma vez que proporciona exteriorização de sua produção. É como o pesquisador comunica aos seus pares seus achados.

\subsection{Avaliação de Artigos}

O artigo científico constitui uma exposição analítica de informações atualizadas sobre um tema de interesse para determinada área do conhecimento. É o resultado de um estudo desenvolvido por meio de uma pesquisa, podendo ser 
através de um projeto de Ensino, de Pesquisa ou de Extensão, sendo seu objetivo o de divulgar os resultados do trabalho realizado, procurando levar ao conhecimento do público interessado novas idéias e abordagens.

Nesse sentido, as publicações em periódicos especializados constituem-se num esforço importante na carreira dos pesquisadores no sentido de proporcionar a exteriorização do pensamento e produção (FREZATTI, 2000). A exposição dos resultados da pesquisa ao julgamento da comunidade científica e sua aprovação por ela proporcionam confiança nos resultados.

Job, Mattos e Trindade (2009) observam que a produção intelectual dos pesquisadores é avaliada pelos membros da comunidade científica e os resultados de seus estudos são enviados para publicação. Segundo os autores, o processo mais comum de avaliação de artigos é o denominado sistema de arbitragem, de avaliação de originais, de avaliação pelos pares ou, em inglês, referee system ou peer review. Tal processo consiste no uso de juízes para auxiliar a avaliação dos trabalhos submetidos para publicação. Assim, com base na maior parte dos sites dos periódicos científicos, o artigo, ao ser submetido, terá três possibilidades de avaliação: aprovado; aceita, mas com necessidade de ajustes; ou rejeitado. Dancik (1991) ressalta que a avaliação é executada por referees que não pertencem ao corpo editorial da revista, pois, com a especialização e o aumento do número de trabalhos, os editores se viram impossibilitados de executar, sem auxílio externo, esta função.

Adicionalmente, Kern e Saraiva (1999) salientam que a decisão sobre a conveniência de aceitar um artigo para publicação é de responsabilidade do editor de um periódico. O responsável geralmente recorre a pesquisadores cuja especialidade relaciona-se ao tópico do artigo e pede seu conselho para subsidiar a decisão. Os revisores são escolhidos de acordo com sua experiência, renome, e experiência anterior como revisor.

Cabe ao editor, ao receber um original, decidir se é compatível ou não com a política editorial do periódico. Em caso positivo, o editor geralmente escolhe o revisor, cabendo-lhe ainda, na maior parte das vezes, a decisão final quanto à publicação de um manuscrito, mesmo após sua revisão (DANCIK, 1991). Por meio do auxílio dos revisores, o trabalho do editor é se certificar de que o estudo tem fundamento, que é um avanço legítimo e inovador, que é apresentado de forma clara e concisa, e que se encontra pertinentemente no contexto.

Assim, o processo de análise de artigos submetidos à apreciação dos avaliadores constitui-se em uma das etapas mais importantes e, portanto mais críticas, considerando tanto a perspectiva do avaliador, como também dos autores dos artigos. De acordo com a maior parte dos sites dos periódicos científicos, geralmente, os artigos submetidos são encaminhados a dois pareceristas especialistas na área do trabalho. Tendo havido divergência na opinião, o artigo é encaminhado 
a um terceiro avaliador.

Para Castro (2006) a vantagem da avaliação por pares é que ela proporciona a detectação de erros metodológicos e de delineamento; omissões e afirmações equivocadas; promove padrões éticos de pesquisa; melhora a qualidade do relato dos dados; aprimora a legibilidade do texto e aperfeiçoa a acurácia das conclusões e afirmações. Contudo, Rowland (2002) argumenta que esse tipo de revisão não detecta a falsificação dos resultados ou plágio de trabalhos, além de sub-reconhecer o trabalho do revisor, já que, em alguns casos, os avaliadores não são impedidos de conhecer a identidade dos autores, embora na maior parte dos periódicos a identidade dos autores não seja revelada.

Alguns periódicos avaliam, inicialmente, se o trabalho submetido se insere no perfil editorial da revista e de seus leitores. Dessa forma, é analisada a área de interesse do tema principal do trabalho, se o título e resumo estão adequados, se a redação está bem elaborada, a metodologia bem definida e correta, se os resultados estão apresentados de maneira clara e conclusões baseadas nos dados. Tal procedimento tem por objetivo reduzir o tempo de resposta e não prejudicar os autores. Desse modo, a resposta elaborada pelos revisores só ocorre quando o artigo passa desta fase inicial. No caso de rejeição, a decisão sobre a primeira fase de avaliação é comunicada aos autores.

Visando aperfeiçoar processo editorial, a Associação Nacional de Pósgraduação e Pesquisa em Administração (ANPAD) elaborou o documento intitulado Boas Práticas da Publicação Científica: um manual para autores, revisores, editores e integrantes de Corpos Editoriais. De acordo com esse trabalho, um periódico científico possui duas preocupações principais, sendo a primeira a de levar aos seus leitores o conhecimento novo e relevante dentro de sua área temática. A outra é fazê-lo a tempo e hora e perenizar-se, ou seja, zelar pela sua própria existência para sempre. Nesse sentido, tais aspectos são garantidos pelo processo editorial, uma série de tarefas sequenciais, que devem ser executadas de modo sistemático e eficiente. Esse processo deve, também, ser transparente, ou seja, na medida do possível, oferecer a possibilidade de acompanhamento pelas partes envolvidas (ANPAD, 2011). Sugere-se que todo periódico tenha um manual do processo editorial contendo a descrição detalhada de cada procedimento da rotina operacional.

De acordo com a Anpad (2011), a boa prática editorial implica, também, celeridade do processo de editoração. Nessa linha, os atores principais desse processo - editores, revisores e autores, devem envidar ações visando a atender aos seguintes prazos máximos em relação à data de submissão: a) até 30 dias, para comunicar aos autores o resultado da revisão de admissão (desk review), que define se o manuscrito passará pelo processo de revisão do periódico; e até 120 dias, para o encaminhamento aos autores do primeiro parecer de cada um dos 
revisores, no caso de manuscritos que tenham sido aceitos no desk review.

Como forma de padronizar a avaliação, determinadas revistas científicas e congressos distribuem formulários, denominados relatórios de revisão, os quais devem ser preenchidos pelos revisores. Tais formulários apresentam um cabeçalho, uma seção de instruções para os revisores e várias seções a serem preenchidas, incluindo: comentários que não são repassados para o autor, avaliação sumária e recomendação (com respostas objetivas), visão geral e comentários detalhados dirigidos ao autor (KERN; SARAIVA, 1999). De acordo com as normas de avaliação e publicação da maioria dos periódicos científicos, ao receber o parecer dos revisores, os autores deverão encaminhar, em comunicado à parte, todos os pontos alterados do artigo que foram solicitados pelos revisores.

O revisor deve decidir se o artigo oferece uma contribuição significativa à ciência e oferecer esta avaliação ao editor, na forma de um relatório de revisão. O relatório é repassado ao autor sem a identificação do revisor, como forma de proporcionar àquele a oportunidade de conhecer a opinião do parecerista. Assim, o autor saberá por que seu artigo foi aceito ou rejeitado e, consequentemente, realizar as alterações sugeridas para a melhoria do artigo (KERN;SARAIVA, 1999).

Judge (1989) coordenou uma pesquisa sobre as revistas eruditas da Austrália para identificar todas as suas características. A pesquisa, realizada por intermédio de questionário, revelou que os periódicos tinham problemas quanto aos procedimentos editoriais, gerenciamento, marketing, distribuição e recursos financeiros. Apontou também que, na maior parte das vezes, o editor selecionava os referees após consulta com editores associados, membros do Conselho Editorial, ou especialistas da área.

Alvarenga (2003) analisou 2.382 citações de 206 artigos da Revista Brasileira de Estudos Pedagógicos (RBEP), de 1944 a 1974, referentes à institucionalização da pesquisa no Brasil, para verificar se havia algum sistema de exclusão de autores no processo de submissão de artigos para publicação no periódico. Concluiu, sobre a existência de claros indícios de que tenha havido fidelidade do periódico à ideologia do estado, tendo seu processo funcionado a partir de um sistema de não publicação de artigos dos autores que não se afinassem com o pensamento estatal representado pelo Ministério da Educação, publicador do periódico.

Bornmann, Nast e Daniel (2008) realizaram uma análise quantitativa do conteúdo de 46 estudos sobre os critérios para a avaliação de manuscritos e os motivos para aceitá-los ou rejeitá-los. O estudo objetivou verificar se os avaliadores consideravam as questões éticas e se detectavam o plágio nos manuscritos. Verificaram que, do total de 572 critérios e fundamentos, nos 46 estudos, divididos em nove áreas principais, nenhum dos critérios ou razões que foram atribuídos, referiam-se, ou estariam relacionados, a possíveis falsificações ou à fabricação 
de dados. Em uma segunda etapa, o estudo solicitou aos editores e pareceristas avaliarem como alto ou baixo o significado de cada aspecto por eles analisado. O critério ético e o plágio não figuraram entre os mais citados.

Job, Mattos e Trindade (2009) analisaram 191 pareceres referentes a artigos enviados a um periódico no período, de 1997 até 2007, com a finalidade de conhecer os motivos que levaram os avaliadores à sua rejeição para publicação. Os autores verificaram que a preocupação central dos pareceristas, ao avaliar um trabalho científico, é com o conteúdo e, principalmente, com os aspectos metodológicos. Dessa forma, os autores salientam que o pesquisador deve estar preparado para a demonstração de seus argumentos, de forma consistente, com resultados e conclusões lógicos e encadeados relacionados aos objetivos a que se propôs, o que frequentemente não ocorreu nos textos rejeitados.

Observa-se que todo o processo pelo qual um artigo passa até ser publicado toma um período de tempo. Atrelado a isso, existe o fato da área do pesquisador contábil ser emergente, sendo o número de periódicos insuficientes para comportar todos os trabalhos submetidos, a existência de um percentual restrito de pesquisadores que possam ser avaliadores.

$\mathrm{Na}$ Contabilidade, observa-se um descompasso entre a disponibilidade de pesquisadores experientes e o crescimento dos periódicos especializados. Desse modo, verifica-se uma insuficiência de avaliadores capacitados para cumprir com a demanda e dar conta da responsabilidade no ritmo que os periódicos desejam (e que precisam cumprir, para manter ou elevar o nível de avaliação conquistado).

Nesse sentido Job, Mattos e Trindade (2009) observam que publicar em periódicos acadêmicos reputados tornou-se mais difícil: o prazo entre recebimento, avaliação e publicação alarga-se e as taxas de rejeição em muitos periódicos são superiores a 90\% dos artigos recebidos. Contudo, para Meadows (1999), a recusa de artigos é comum e necessária, pois o mesmo artigo se recusado pode ser submetido a diferentes periódicos, ocorrendo assim um processo de depuração e aprimoramento.

A periodicidade regular de publicação e o período de avaliação dos artigos consistem em um dos critérios de importância fundamental no processo de revisão, uma vez que a habilidade da publicação pontual permite a viabilidade de uma publicação, tendo em vista que um número considerável de artigos permitirá a continuidade da mesma. Para Garfield (1994) não é aceitável um periódico ser publicado com atraso, meses depois da data de sua abrangência, ou que o período pelo qual um artigo passe por revisão seja alto.

\section{Procedimentos Metodológicos}

A presente pesquisa é do tipo descritiva e a estratégia usada para atender 
ao objetivo estabelecido foi a pesquisa documental. Conforme Gall et al. (2007), a pesquisa descritiva envolve a descrição de um fenômeno social ou natural: sua forma, estrutura, atividade, mudanças e relacionamentos ao longo do tempo, dentre outros. Sampieri et al. (2006) ressaltam que os estudos descritivos pretendem medir ou coletar informações de maneira independente ou conjunta sobre os conceitos ou as variáveis a que se referem.

Quanto ao método, a pesquisa documental caracteriza-se pelo uso de documentos como fontes de dados, informações e evidências (MARTINS; THEÓFILO, 2007). Dessa forma, o estudo teve como base de dados os artigos contidos nos periódicos dos cursos de pós-graduação stricto sensu na área de Contabilidade existentes no Brasil entre os anos de 2004 a 2009, os quais foram identificados durante 22 de dezembro de 2009 a 10 de dezembro de 2010. O período escolhido se deve ao fato da maior parte dos periódicos vinculados aos cursos de pós-graduação stricto sensu em Contabilidade terem sido criados a partir do ano de 2004 (Quadro 1).

Entre tais cursos de pós-graduação, 13 possuem periódicos vinculados. Nesse sentido, buscou-se analisar o período de avaliação e publicação de artigos submetidos a esses mecanismos de divulgação científica. Os periódicos Revista de Informação Contábil, vinculado ao curso de mestrado da Universidade Federal de Pernambuco, Revista de Contabilidade da UFBA, vinculada ao mestrado da Universidade Federal da Bahia e Revista Contabilidade e Controladoria da Universidade Federal do Paraná não forneciam a informação sobre o prazo em que o artigo foi aceito e publicado. Por esse motivo esses periódicos foram excluídos da análise.

Tabela 1 - Periódicos analisados

\begin{tabular}{|l|l|l|}
\hline \multicolumn{1}{|c|}{ Periódico } & $\begin{array}{c}\text { Instituição de Ensino } \\
\text { Superior }\end{array}$ & $\begin{array}{l}\text { Quantidade de artigos } \\
\text { analisados }\end{array}$ \\
\hline BASE & UNISINOS & 110 \\
\hline Brazilian Business Review (BBR) & FUCAPE & 71 \\
\hline Contabilidade e Finanças & USP & 127 \\
\hline Contabilidade Vista e Revista & UFMG & 96 \\
\hline Revista Brasileira de Gestão e Negócios (RBGN) & UNIFECAP & 87 \\
\hline Revista Contabilidade e Organizações (RCO) & USP-RP & 50 \\
\hline $\begin{array}{l}\text { Revista de Contabilidade do Mestrado em Ciências } \\
\text { Contábeis }\end{array}$ & UERJ & 10 \\
\hline Universo Contábil & FURB & 109 \\
\hline TOTAL & & 660 \\
\hline
\end{tabular}

Fonte: Dados da pesquisa. 
Além disso, os artigos referentes à Revista Contemporânea de Contabilidade, vinculada ao curso da Universidade de Santa Catarina e a UNB Contábil, ligada ao programa de mestrado/doutorado na Universidade de Brasilia, não apresentavam a data especifica em que o trabalho foi aceito e publicado. Desse modo, essas revistas também não foram consideradas na análise. Os periódicos que compuseram a amostra final do presente estudo e o número de artigos analisados são apresentados na Tabela 1.

As informações foram coletadas no site dos periódicos, buscando primeiro os artigos publicados, após fez-se a apuração das datas referentes ao período de avaliação, desde o aceite até a publicação. Foi verificado o lapso temporal entre a submissão e publicação de 660 artigos publicados nos periódicos supracitados entre os anos de 2004 e 2009. As variáveis analisadas foram: a data de recebimento do artigo, a data de aceitação, as datas de revisão e da aceitação da segunda versão e, por fim, a data da publicação do estudo científico.

No caso em que a data de publicação não foi evidenciada nos periódicos utilizou-se como proxy o último dia do mês que se referia o período da revista como data da publicação. Por exemplo, se uma revista possuía periodicidade trimestral, a data de publicação considerada do primeiro volume anual foi 30 de março, último dia do trimestre janeiro-março. Foi aplicada a mesma metodologia em todos os períodos (trimestrais, quadrimestrais, semestrais).

O trabalho de coleta e operacionalização das informações foi divido entre a coleta dos artigos no site dos periódicos, apuração das datas referentes ao período de avaliação, tabulação dessas informações na planilha eletrônica Excel® e análise.

\section{Análise dos Resultados}

De acordo com Oliveira (2002) a periodicidade da revista é uma informação relevante para os pesquisadores que pretendem mandar artigos para publicação, já que tal fato representa uma agilidade na circulação da informação científica. Além disso, ressalta-se que o tempo de existência dos periódicos e sua classificação são fatores que podem interferir no período de tempo decorrido entre a submissão do artigo e sua publicação. Revistas com maior tempo de existência e melhor classificação no estrato Qualis/CAPES podem ter um maior número de submissões, inicialmente, por já estarem estabelecidos há mais tempo e também por atribuírem maior pontuação ao autor. Ressaltando que a pontuação é um dos critérios de avaliação da CAPES dos cursos e profissionais de pós-graduação stricto sensu.

Assim, inicialmente, foi identificado o ano de criação do periódico e sua classificação no estrato Qualis/CAPES, bem como a periodicidade em cada revista 
é publicada. Tais informações podem ser vistas no Quadro 1.

Quadro 1 - Periodicidade das revistas

\begin{tabular}{|l|l|l|l|}
\hline \multicolumn{1}{|c|}{ Periódico } & Periodicidade & $\begin{array}{l}\text { Ano de } \\
\text { criação }\end{array}$ & $\begin{array}{l}\text { Clas s ific açã o } \\
\text { Qualis/CAPES }\end{array}$ \\
\hline BASE & Quadrimestral & 2004 & B2 \\
\hline Brazilian Business Review (BBR) & Semestral & 2004 & B2 \\
\hline Contabilidade e Finanças & Trimestral & 1989 & B1 \\
\hline Contabilidade Vista e Revista & Quadrimestral & 1989 & B3 \\
\hline Revista Brasileira de Gestão de Negócios (RBGN) & Trimestral & 1998 & B3 \\
\hline Revista Contabilidade e Organizações (RCO) & Quadrimestral & 2007 & B3 \\
\hline $\begin{array}{l}\text { Revista de Contabilidade do Mestrado em Ciências } \\
\text { Contábeis }\end{array}$ & Quadrimestral & 2007 & B4 \\
\hline Universo Contábil & Trimestral & 2005 & B3 \\
\hline & & & \\
\hline
\end{tabular}

Fonte: Dados da pesquisa.

Verificou-se que os periódicos vinculados aos cursos de pós-graduação em Ciências Contábeis não possuem a mesma periodicidade. Os periódicos Contabilidade Vista e Revista (UFMG) e Universo Contábil (FURB) foram os periódicos que apresentaram a maior quantidade de edições por ano, quatro edições anuais. Destaca-se que a RBGN (UNIFECAP) teve periodicidade quadrimestral até o ano de 2007, sendo que a partir deste período, iniciou a publicação de quatro volumes por ano, passando a ter periodicidade trimestral.

A maior parte das revistas publica três edições anuais, isto é, possuem periodicidade quadrimestral. Destaca-se que a Brazilian Business Review (FUCAPE) e a Revista de Contabilidade do Mestrado em Ciências Contábeis (UERJ) publicam apenas duas revistas por ano. Diante dessas informações é possível observar que o número de edições das revistas é escasso, dificultando ainda mais a divulgação científica na área contábil.

De acordo com as informações constantes na Tabela 2, observa-se, na maior parte dos periódicos $(88 \%)$, um gradativo aumento no período compreendido ente a data do recebimento e a data de aceitação do trabalho científico. Nesse sentido, observou-se que, entre os anos de 2004 e 2006, o periódico Contabilidade e Finanças (USP) foi o que levou maior tempo para avaliar um artigo submetido, desde seu recebimento até sua aceitação. Infere-se que tal fato pode ser explicado pela pontuação da referida revista no estrato Qualis/CAPES, o que pode levar a uma maior quantidade de trabalhos submetidos.

Na Tabela 2 estão demonstrados os períodos médios decorridos entre a data do recebimento do artigo pelo periódico e a data de aceitação para publicação. 
Tabela 2 - Período médio (em dias) entre a data de recebimento e a data de aceitação

\begin{tabular}{|l|r|r|r|r|r|r|}
\hline Periódico & 2004 & 2005 & 2006 & 2007 & 2008 & 2009 \\
\hline BASE & 47 & 69 & 135 & 288 & 334 & 443 \\
\hline Brazilian Business Review (BBR) & - & 35 & 135 & 90 & 164 & 233 \\
\hline Contabilidade e Finanças & 171 & 101 & 135 & 180 & 166 & 166 \\
\hline Contabilidade Vista e Revista & - & - & 46 & 69 & 115 & 174 \\
\hline Revista Brasileira de Gestão e Negócios (RBGN) & - & - & 143 & 166 & 206 & 264 \\
\hline Revista Contabilidade e Organizações (RCO) & - & - & - & 28 & 45 & 76 \\
\hline $\begin{array}{l}\text { Revista de Contabilidade do Mestrado em Ciências } \\
\text { Contábeis }\end{array}$ & - & - & - & - & - & 168 \\
\hline Universo Contábil & - & - & 103 & 132 & 282 & 304 \\
\hline
\end{tabular}

Fonte: Dados da pesquisa.

A partir de 2006, o período entre o recebimento e a aceitação de um trabalho da revista Base (UNISINOS) foi superior ao tempo de todos os outros periódicos analisados. Este mesmo periódico foi o que apresentou maior aumento no tempo na avaliação de um artigo. No ano de 2004 o periódico demorou, em média, 47 dias para analisar um trabalho científico desde seu recebimento até sua aceitação. Já em 2009, esse período foi de 443 dias, representando um aumento de 943\% no tempo de avaliação dos manuscritos submetidos. A BBR (FUCAPE) também apresentou um aumento considerável, sendo que a elevação foi de $666 \%$ de 2005 para 2009. A revista Universo Contábil (FURB) foi o segundo periódico que demorou mais para avaliar um trabalho, sendo que em 2009 o artigo submetido a esse periódico levou, em média, 304 dias entre a submissão e aceitação.

Referente ao menor tempo para avaliar um trabalho, a RCO (USP-RP) foi a que apresentou o menor tempo, sendo que, em 2007 esse período foi de 28 dias e em 2009 foi de 76 dias. Tal revista demonstra uma velocidade maior para analisar os artigos quando comparada com as outras publicações. Como já comentado, o tempo de existência da revista e a pontuação no Qualis/CAPES podem ser influenciadores da quantidade de trabalhos submetidos e, consequemente, no tempo de avaliação destes. Assim, o fato da Revista Contabilidade e Organizações (USP-RP) ter sido recentemente criada e possuir pontuação B3 no Qualis/CAPES podem explicar o menor tempo entre o recebimento e a aceitação de um artigo. Após a RCO (USP-RP), o periódico Contabilidade Vista e Revista (UFMG) apresentou o menor tempo entre o recebimento e aceitação de uma pesquisa, sendo que nos anos de 2006 e 2007 esse período foi de 45 e 69 dias, respectivamente.

Após o recebimento e a realização das revisões dos avaliadores, o trabalho é aceito para publicação. Contudo, pode haver a necessidade de alterações sugeridas pelos avaliadores para que o trabalho seja publicado. Tal fato é representado pelo tempo decorrido entre a revisão do artigo pelos pareceristas, com sugestões de 
melhoria, as alterações implementadas pelo autor e a publicação. Cabe ressaltar que apenas as revistas Contabilidade Vista e Revista (UFMG) e Contabilidade e Finanças (USP) apresentam tal informação em suas publicações, demonstrando a data em que a segunda versão dos trabalhos foi aceita.

Dessa forma, verificou-se que no ano de 2004 os trabalhos submetidos à Revista Contabilidade e Finanças (USP) levou um tempo médio de 84 dias para que sua segunda versão, após ajustes do autor, fosse aceita. Após cinco anos esse prazo se elevou para 127 dias, representando um aumento de $66 \%$. Já a Contabilidade Vista e Revista (UFMG) em 2008 gastou, em média, 61 dias par aceitar a segunda versão dos trabalhos. No ano seguinte o prazo passou para 47 dias.

Nesse sentido, Job, Mattos e Trindade (2009) destacam a preocupação dos pareceristas, ao avaliar um trabalho científico, com o conteúdo e, principalmente, com os aspectos metodológicos. De acordo com os autores o pesquisador deve demonstrar seus trabalhos de forma consistente, com resultados e conclusões lógicos e encadeados relacionados aos objetivos a que se propôs.

Tabela 3 - Período médio (em dias) entre a data de aceitação e a data de publicação

\begin{tabular}{|l|l|l|l|l|l|l|}
\hline Periódico & 2004 & 2005 & 2006 & 2007 & 2008 & 2009 \\
\hline BASE & 58 & 93 & 84 & 83 & 66 & 107 \\
\hline Brazilian Business Review (BBR) & - & 28 & 74 & 85 & 27 & 27 \\
\hline Contabilidade e Finanças & 132 & 172 & 213 & 205 & 343 & 371 \\
\hline Contabilidade Vista e Revista & - & - & 14 & 39 & 85 & 78 \\
\hline Revista Brasileira de Gestão e Negócios (RBGN) & - & - & 80 & 68 & 118 & 106 \\
\hline Revista Contabilidade e Organizações (RCO) & - & - & - & 5 & 26 & 10 \\
\hline $\begin{array}{l}\text { Revista de Contabilidade do Mestrado em Ciências } \\
\text { Contábeis }\end{array}$ & - & - & - & - & - & 20 \\
\hline Universo Contábil & - & - & 107 & 168 & 157 & 263 \\
\hline
\end{tabular}

Fonte: Dados da pesquisa.

Após a aceitação, inicia-se o processo de publicação, o qual poderá incorrer mais algum tempo antes da efetiva circulação da revista. A Tabela 3 apresenta $o$ tempo médio que os periódicos levam para publicar os manuscritos submetidos após serem aceitos.

Referente ao período entre a data de aceitação do artigo e a efetiva data de publicação, a revista Contabilidade e Finanças (USP) foi a que apresentou maior dispêndio de tempo durante todos os anos pesquisados. Destaca-se que o tempo médio gasto por este periódico para publicar um trabalho após sua aceitação evoluiu constantemente durante o período analisado, passando de 132 dias em 2004 para $371 \mathrm{em} 2009$. Esse crescimento foi de $181 \%$. Ressalta-se que o referido 
periódico foi o único a gastar mais de um ano para publicação de pesquisas após sua aceitação, fato ocorrido no ano de 2009.

Por outro lado, verificou-se que a RCO (USP-RP) foi o periódico que demonstrou o menor tempo entre a aceitação de um artigo e sua publicação. No ano de 2007, esse período foi de 5 dias. Já nos anos de 2008 e 2009 esse período correspondeu a 26 e 10 dias, respectivamente. Destaca-se que tal fato pode estar relacionado com a maturidade e classificação da revista no estrato Qualis/CAPES, bem como o número de artigos submetidos.

Analisando anualmente, encontrou-se que, em 2005, a BBR foi a revista que gastou o menor tempo para publicar o artigo após sua aceitação, sendo que o prazo médio foi de 28 dias. Já no ano de 2006 o menor período foi apresentado pelo periódico Contabilidade Vista e Revista, que gastou 14 dias. Já nos anos seguintes, a RCO foi a que apresentou os menores períodos para publicação dos trabalhos após os mesmos serem aceitos.

Na Tabela 4 está evidenciado o tempo decorrido durante todo o processo entre a submissão e a publicação de um trabalho.

Tabela 4 - Período médio (em dias) entre a data de recebimento e a data de publicação

\begin{tabular}{|l|l|l|l|l|l|l|}
\hline Periódico & 2004 & 2005 & 2006 & 2007 & 2008 & 2009 \\
\hline BASE & 105 & 162 & 219 & 371 & 399 & 550 \\
\hline Brazilian Business Review (BBR) & - & 63 & 208 & 175 & 191 & 260 \\
\hline Contabilidade e Finanças & 303 & 273 & 348 & 385 & 509 & 537 \\
\hline Contabilidade Vista e Revista & - & - & 60 & 108 & 200 & 252 \\
\hline Revista Brasileira de Gestão e Negócios (RBGN) & - & - & 223 & 234 & 324 & 370 \\
\hline Revista Contabilidade e Organizações (RCO) & - & - & - & 32 & 71 & 86 \\
\hline $\begin{array}{l}\text { Revista de Contabilidade do Mestrado em Ciências } \\
\text { Contábeis }\end{array}$ & - & - & - & - & - & 188 \\
\hline Universo Contábil & - & - & 210 & 299 & 439 & 567 \\
\hline
\end{tabular}

Fonte: Dados da pesquisa.

No que se refere ao tempo necessário para avaliação e publicação dos artigos, isto é, a diferença entre o recebimento do trabalho e a publicação do mesmo, verificou-se que, de modo geral, o período necessário pelas revistas para realização de tal procedimento elevou-se como o passar do tempo. Tal fato pode ser decorrente de um número cada vez maior de pesquisas advindas de novos cursos de pós-graduação stricto sensu em Contabilidade, e aumento da quantidade de mestres e doutores.

A revista Base (UNISINOS) foi a que apresentou maior aumento percentual no período entre a data de recebimento e a data de publicação. Em 2004 o tempo médio gasto em tal processo foi de 105 dias, sendo que em 2009 tal prazo 
correspondeu a 550 dias, representando um aumento de mais de 400\%. Em seguida o periódico Contabilidade Vista e Revista (UFMG) apresentou um aumento superior a $300 \%$ de 2004 a 2009.

Nesse quesito, o periódico RCO (USP-RP) foi o que apresentou menor dispêndio de tempo para avaliar e publicar as pesquisas, sendo que a revista apresentou média inferior a três meses no processo de recebimento, avaliação e publicação dos trabalhos. Nesse sentindo, um artigo recebido em 2007 levou 32 dias para ser publicado. Esse período aumentou para 71 e 86 dias nos anos 2008 e 2009, respectivamente.

Por outro lado, a revista Contabilidade e Finanças (USP), com exceção do ano de 2009, foi a que apresentou maior tempo na realização do processo de recebimento do artigo até sua publicação. O tempo gasto pela respectiva revista era de 303 dias em 2004, passando para 385 dias em 2007 e chegando a 537 dias em 2009.

Ressalta-se, ainda, que as revistas Base (UNISINOS), Universo Contábil (FURB) e Contabilidade e Finanças (USP), apresentaram, nos anos de 2007, 2008 e 2009, tempo superior a um ano para avaliação e publicação dos trabalhos recebidos. Tais periódicos foram os que necessitaram de maior tempo no processo de recebimento, avaliação e publicação dos artigos, sendo que no ano de 2009 a realização de tal processo, por parte destas revistas, superou quinhentos dias.

\section{Considerações Finais}

A produção e a divulgação dos resultados das pesquisas favorecem a expansão do saber. Nesse sentido, a publicação de uma pesquisa acadêmica constitui-se num dos caminhos mais importantes de disseminação do conhecimento científico, sendo que os periódicos são canal relevante de comunicação entre os pesquisadores e a comunidade. Contudo, é importante que a evidenciação das pesquisas seja realizada em tempo oportuno para que os estudos não percam a tempestividade e contribuam para o avanço da pesquisa.

Assim, o presente estudo objetivou buscar evidências que permitissem identificar e analisar o período de avaliação e publicação de artigos em periódicos científicos da área de Contabilidade. Para tanto, realizou-se um estudo descritivo com utilização da estratégia de pesquisa documental em 660 artigos distribuídos em oito periódicos, vinculados aos cursos de pós-graduação stricto sensu em Ciências Contábeis, no período de 2004 a 2009. Assim, identificou-se, em cada artigo, a data de recebimento do artigo, a data de aceitação, as datas de revisão e da aceitação da segunda versão e, por fim, a data da publicação do estudo científico.

Observou-se que, existem discrepâncias na periodicidade das revistas 
analisadas, sendo escasso o número de edições dos periódicos. Ressalta-se a importância de um aumento na quantidade de edições anuais de tais periódicos.

Constatou-se que a revista Contabilidade e Finanças (USP), vinculada ao programa de pós-graduação stricto sensu da Universidade de São Paulo, apresentou o maior tempo médio gasto entre o recebimento de artigo e sua publicação. Por outro lado, a revista RCO (USP-RP), atrelada ao curso de pós-graduação stricto sensu da Universidade de São Paulo de Ribeirão Preto, foi o periódico que apresentou o menor tempo para avaliar um artigo. Os resultados vão ao encontro da expectativa de que publicar em periódicos acadêmicos reputados torna-se cada vez mais difícil (JOB; MATTOS; TRINDADE, 2009).

Por meio do estudo, verificou-se que, o tempo gasto no processo de avaliação e publicação de um artigo tem aumentado consideravelmente no decorrer dos anos. Assim, a cada ano, os trabalhos científicos na área de Contabilidade demoram mais a serem divulgados nos periódicos analisados.

Entre os motivos para essa constatação, infere-se que a classificação da revista no sistema Qualis/CAPES influenciaria no período de avaliação, já que, visando atender às exigências de tal órgão, os pesquisadores tendem a enviar seus trabalhos para os periódicos com maior pontuação. Como exemplo, verificou-se que a Revista de Contabilidade e Finanças (USP), o periódico de contabilidade com maior classificação no sistema Qualis/CAPES, que se encontra nos estratos mais altos da classificação, apresenta-se como o periódico que gasta mais tempo em seu processo de avaliação, possivelmente, por receber o maior número de trabalhos.

Outro fator que parece relacionar-se com o tempo decorrido na avaliação e publicação de artigos na área de Contabilidade é a maturidade do periódico. Assim, a Revista de Contabilidade e Organizações (USP-RP), que apresenta o menor tempo de avaliação e publicação de trabalhos, está entre as revistas mais recentes, criada em 2007. Por outro lado, a Revista de Contabilidade e Finanças (USP) é a revista mais antiga, juntamente com a Contabilidade Vista e Revista (UFMG), fundadas em 1989. Ambos os periódicos apresentaram, em comparação com as outras revistas, um período maior de análise dos artigos submetidos.

Ressalta-se, ainda, que o reduzido número de doutores faz com que a equipe de avaliadores à disposição dos periódicos seja composta, muitas vezes, pelos mesmos indivíduos. Esse aspecto também pode ser considerado um dos fatores que interferem no tempo de avaliação dos artigos submetidos nos periódicos da área de Contabilidade, uma vez que pode haver uma sobrecarga de trabalhos a serem avaliados para cada avaliador, aumentando o período de revisão dos mesmos.

O aumento relevante da produção científica na área de Contabilidade nos últimos anos também pode ser considerado como causa para o elevado período de tempo em que um artigo passa pelo processo de revisão. Por último, percebe-se 
que a nova política de avaliação da Qualis/CAPES, que reduziu a pontuação dos congressos científicos, contribui para o aumento da quantidade de artigos submetidos dos periódicos. Dessa forma, devido ao baixo número de revistas nacionais pontuadas na área de Contabilidade, os pesquisadores procuram submeter seus trabalhos em revistas de outras áreas.

Assim, sugere-se, para futuros estudos, a análise das causas que proporcionam o aumento no período de revisão e publicação dos artigos submetidos nos periódicos. Recomenda-se, ainda, a replicação deste estudo em outros periódicos, buscando identificar possíveis semelhanças e diferenças no período e no método de avaliação dos periódicos em Contabilidade e/ou áreas afins.

\section{Referências}

ALMEIDA, Lauro Brito; PARISI, Cláudio; PEREIRA, Carlos Alberto. ControlaALVARENGA, L. Política e editorial e estado: estudo bibliométrico de artigos publicados na revista brasileira de estudos pedagógicos. Informação e sociedade, João Pessoa, v. 13, n. 1, p. 79-120, jan./jun. 2003.

ASSOCIAÇÃO NACIONAL DOS PROGRAMAS DE PÓS-GRADUAÇÃO EM CIÊNCIAS CONTÁBEIS-ANPCONT. Disponível em: www.anpcont.com.br. Acesso em: 04 dez. 2009.

ANGERAMI, E. L. S.; ALMEIDA, M. C. P. Divulgação do conhecimento científico produzido na enfermagem. Avaliação e perspectivas, CNPq/ABEn, Brasília, , p. 108-127, 1982.

ANTUNES, E. D. D.; ARAMBURÚ, J. V.; VIEIRA, M. C.; OLIVEIRA, S. R.; \& MACKE, J. Trajetória das dissertações em gestão de pessoas de um curso de pós-graduação do sul do país: caminhos de uma tradição de pesquisa e atalhos para a renovação. In: XXVIII Encontro da Associação Nacional dos Programas de Pós-graduação em Administração (ENANPAD), Curitiba. Anais... Paraná: ENANPAD, 2004.

BORBA, J. A.; MURCIA, F. D. Possibilidades de Inserção da Pesquisa Contábil Brasileira no Cenário Internacional: Uma Proposta de Avaliação dos Periódicos Científicos de Contabilidade e Auditoria Publicados em Língua Inglesa e disponibilizados no Portal de Periódicos da CAPES. Brazilian Business Review, v. 3. n. 1, jan. / jun., 2006.

BORNMANN, L.; NAST, I.; DANIEL, H. Do editors and referees look for signs of scientific misconduct when reviewing manuscripts? A quantitative content analysis 
of studies that examined review criteria and reasons for accepting and rejecting manuscripts for publication. Scientometrics, v. 77, n. 3, p. 415-432, 2008.

CARVALHO, T. A produção científica brasileira em odontologia e sua visibilidade nacional e internacional. Tese (Doutorado em Ciência da Informação). Programa de Pós-Graduação em Ciência da Informação. Escola de Comunicações e Artes da Universidade de São Paulo. São Paulo, 2006.

CASTRO, R. C. F. Revistas de cirurgia e gastroenterologia: indexação em bases de dados e indicadores bibliométricos. Acta Cirúrgica Brasileira, v. 21, n. 3, p. 128-132, 2006.

CHRISTOVÃO, H. T.; BRAGA, G. M. Ciência da Informação e Sociologia do Conhecimento Científico: a intertematicidade plural (Sobre "A ciência e seu público" de Léa Velho: um ponto de vista de Ciência da Informação). Transinformação, v. 9, n 3, p. 33 - 45, 1997.

COORDENAÇÃO DEAPERFEIÇOAMENTO DO PESSOAL DE NÍVEL SUPERIOR - CAPES. Disponível em: www.capes.gov.br. Acesso em: 29 nov. 2009.

DANCIK, B.P. The importance of peer review. The Serials Librarian, v. 19, p. 91-94, 1991.

FACHIN, G. R. B.; \& HILLESHEIM, A. I. A. Publicação periódica: revendo padrões de publicação e avaliação de artigos. In: I Conferência Ibero-americana de Publicações Eletrônicas no Contexto da Comunicação Científica. Brasília, Anais... Distrito Federal, 2006.

FREZATTI, F. Análise dos traços de tendência de uma amostra das revistas cientificas da área de contabilidade publicadas em língua inglesa. Caderno de Estudos FIPECAFI, São Paulo, v.13, n. 24, p. 50 - 78, jul./dez., 2000.

GALL, M. D.; GALL, J. P.; BORG, W. R. Educational research: an introduction. 8th. ed. Person/Allyn and Bacon, 2007.

GARFIELD, E. The impactor factor. Current Contents, v. 25, p. 3-8, jun., 1994.

GARVEY, W. D. Communication: the essence of science. London: Pergamon Press, 1979.

JOB, I.; MATTOS, A. M.; TRINDADE, A. Processo de revisão pelos pares: por que são rejeitados os manuscritos submetidos a um periódico científico? Movimento, Porto Alegre, v. 15, n. 03, p. 35-55, jul. / set., 2009. 
JUDGE, J. Australian scholarly journals: an unseen crisis. The Serials Librarian, v. 16, p. 119-154, 1989.

KERN, V. M.; SARAIVA, L. M. Aplicação da revisão pelos pares no ensino de graduação. Alcance, Itajaí, v. 4, n. 3, p. 42-49, nov., 1999.

LOWE, A.; LOCKE, J. Perceptions of journal quality and research paradigm: results of a web-based survey of British accounting academics. Accounting Organizations and Society, v. 30, p. 81-98, 2005.

MARCHIORI, P. Z.; ADAMI, A.; FERREIRA, S. M. Fatores motivacionais da comunidade científica para publicação e divulgação de sua produção em revistas científicas. In: VII Simpósio Regional da Pesquisa em Comunicação, 2006. Disponível em: http://www.comtec.pro.br/prod/artigos/fulvio_fatores.pdf. Acesso em: 12 dez. 2009.

MARTINS, G. A. Editorial. Revista de Contabilidade e Finanças, São Paulo, v. 19, n. 48, p. 1 -5, set. / dez., 2008.

MARTINS, G. A.; THEÓFILO, C. R. Metodologia da investigação científica para Ciências Sociais Aplicadas. São Paulo: Atlas, 2007.

MEADOWS, A. J. A comunicação científica. Brasília: Briquet de Lemos, 1999.

MENDONÇA NETO, O. R.; CARDOSO, R. L.; RICCIO, E. L.; \& SAKATA, M. C. G. Estudo sobre as sobre as publicações cientificas em contabilidade: uma análise de 1990 até 2003. In: XXVIII Encontro da Associação Nacional dos Programas de Pós-graduação em Administração (ENANPAD), 2004, Curitiba. Anais... Paraná: ENANPAD, 2004.

MUELLER, S. P. M. A ciência, o sistema de comunicação científica e a literatura científica. In: CAMPELLO, B. S.; CENDÓN, B. V.; KREMER, J. M. (org.). Fontes de informação para pesquisadores e profissionais. Belo Horizonte: Ed. UFMG, 2000.

MUELLER, S. P. M.; CAMPELLO, B. S.; \& DIAS, E. J. W. Disseminação da pesquisa em ciência da informação e biblioteconomia no Brasil. Ciência da Informação - Vol 25, número 3, 1996.

OLIVEIRA, M. Análise dos periódicos brasileiros de contabilidade. Revista de Contabilidade \& Finança, São Paulo, n. 29, p. 68-86, 2002.

PRATHER, J.; RUESCHHOFF. An analysis of international accounting research 
in U.S. academic accounting journals, 1980 through 1993. Accounting Horizons. v. 10, n. 1, p. $1-17$, march, 1996.

ROCHA, E. M. P.; FERREIRA, M. A. T. Indicadores de ciência, tecnologia e inovação: mensuração dos sistemas de CTeI nos estados brasileiros. Ciência da Informação, Brasília, 33 (3), 61- 68, 2004.

ROWLAND, F. The peer-review process. Learned Publishing, v. 15, p. 247-258, 2002.

SABADINI, A. Z. P. I; SAMPAIO, M. I. C.; KOLLER, S. H. Publicar em psicologia: um enfoque para a revista científica. São Paulo: Associação Brasileira de Editores Científicos de Psicologia Instituto de Psicologia da Universidade de São Paulo, 2009.

SAMPIERI, R. H.; COLLADO, C. H.; LUCIO, P. B. Metodologia de pesquisa. 3. ed. São Paulo: McGraw-Hill, 2006.

SILVA, H. C. O que é divulgação científica? Revista Ciência \& Ensino, v. 1, n. 1, dez., 2006.

TARGINO, M. G. Divulgação de resultados como expressão da função social do pesquisador. Revista de Biblioteconomia de Brasília, v. 23/24, n. 3, p. 347-366, $\mathrm{n}^{\mathrm{o}}$ especial, 1999/2000.

TAHAI, A.; RIGBSY, J. Information processing using citation to investigate journal influence in accounting. Information Processing \& Management. v. 34, n. 2, p. 341-359, 1998.

VALÉRIO, P. M. C. M. Comunicação científica e divulgação científica: possível convergência de públicos nas redes eletrônicas. Tese (Doutorado em Ciências da Informação). Programa de Pós-graduação em Ciência da Informação, Faculdade de Ciência da Informação da Universidade Federal do Rio de Janeiro. Rio de Janeiro, 2005.

ZEFF, S. A study of academic research journals in accounting. Accounting Horizons, v. 10, n. 3, p. 158-177, 1996. 